\title{
Espaçamento entre linhas e severidade da ferrugem-asiática da soja
}

\author{
Alexandre Dinnys Roese, Carlos Lasaro Pereira de Melo, Augusto César Pereira Goulart
}

Embrapa Agropecuária Oeste. BR 163, km 253,6. Caixa Postal 449, 79804-970, Dourados, MS.

Autor para correspondência: Alexandre Dinnys Roese (alex@cpao.embrapa.br)

Data de chegada: 16/03/2012. Aceito para publicação em: 25/10/2012.

\section{RESUMO}

Roese, A.D.; Melo, C.L.P.; Goulart, A.C.P. Espaçamento entre linhas e severidade da ferrugem-asiática da soja. Summa Phytopathologica, v.38, n.4, p.300-305, 2012.

No Brasil, a cultura da soja é tradicionalmente semeada em linhas espaçadas de $45 \mathrm{~cm}$ a $50 \mathrm{~cm}$. Alterações nesse espaçamento podem mudar o micro clima e a eficiência de aplicação de fungicidas. Este trabalho teve como objetivo estudar a influência de diferentes espaçamentos na severidade da ferrugem-asiática e na produtividade das cultivares de soja BRS 256 RR, BRS 246 RR e BRS 318 RR, respectivamente nas safras 2007/2008,2009/2010 e 2010/2011. Foram avaliados quatro espaçamentos entre linhas $(35,45,55$ e 65 $\mathrm{cm})$, com e sem aplicação de fungicida na parte aérea das plantas.
Confirmou-se a eficiência do fungicida no controle da doença nas três safras e observou-se que o espaçamento entre linhas não foi significativo para nenhuma variável avaliada na primeira safra do experimento, quando a doença iniciou antes do florescimento. $\mathrm{Na}$ segunda e terceira safras, quando a doença iniciou no florescimento pleno e a severidade final foi menor que na primeira safra, o espaçamento entre linhas influenciou a produtividade nas parcelas sem fungicida da cultivar BRS 246 RR (na segunda safra) e a severidade da doença na cultivar BRS 318 RR (na terceira safra).

Palavras-chave adicionais: arranjo de plantas, Phakopsora pachyrhizi, Glycine Max, controle cultural.

\section{ABSTRACT}

Roese, A.D.; Melo, C.L.P.; Goulart, A.C.P. Row spacing and Asian soybean rust severity. Summa Phytopathologica, v.38, n.4, p.300-305, 2012.

In Brazil, soybeans are traditionally sown in rows spaced from 45 to $50 \mathrm{~cm}$. Changes in such a spacing may alter the microclimate and the efficiency of fungicide application. This study aimed to verify the influence of different row spaces on the severity of soybean rust and on the grain yield of soybean cultivars BRS 256 RR, BRS 246 RR and BRS 318 RR, respectively, in 2007/2008, 2009/2010 and 2010/ 2011 crop seasons. Four row spaces $(35,45,55$ and $65 \mathrm{~cm})$ were tested, with and without fungicide spraying over the shoot of plants.
The efficiency of fungicide spraying was confirmed for disease control in the three crop seasons and row spacing was not significant for any variable assessed in the first crop season, when the disease started before flowering. In the second and third crop seasons, when the disease started during full flowering and the severity was lower than in the first crop season, row spacing influenced the yield in plots without fungicide for cultivar BRS 246 RR (second crop season) and the disease severity for cultivar BRS 318 RR (third crop season).

Additional keywords: plant arrangement, Phakopsora pachyrhizi, Glycine max, cultural control.

A ferrugem-asiática da soja, causada pelo fungo Phakopsora pachyrhizi Syd. \& P.Syd., tem sido, desde sua detecção no Brasil (25), um dos principais desafios fitopatológicos para essa cultura. Até o momento, a única forma de controle da doença, após sua instalação na lavoura, é por meio da aplicação de fungicidas, o que onera os custos da lavoura. Além disso, o seu uso contínuo, como única estratégia de manejo, pode causar a seleção de patógenos resistentes ou menos sensíveis aos fungicidas utilizados e, por conseguinte, a ineficiência do controle da doença, com a aplicação exacerbada de fungicidas e elevação dos custos de produção.

Dessa forma, é necessária a combinação de outras práticas agrícolas para o controle mais efetivo das doenças, a fim de garantir a eficiência econômica e ambiental da agricultura. Neste contexto, a adoção do manejo integrado torna-se uma estratégia adequada para atender ao propósito de eficiência e sustentabilidade no controle de doenças. No entanto, pouco avanço se obteve no conhecimento sobre o manejo cultural da ferrugem-asiática da soja, principalmente com relação ao arranjo de plantas.

O efeito do arranjo de plantas e do espaçamento entre linhas de semeadura tem sido estudado por diversos pesquisadores para as mais variadas culturas $(3,4,5,8,11,12,13,14,15,16,17,22)$. Na cultura da soja, o espaçamento entre linhas interfere na população e crescimento de plantas daninhas (3), no índice de área foliar, na velocidade de fechamento das entrelinhas (13) e no rendimento de grãos $(12,14)$. No entanto, pouco se tem estudado sobre o efeito de espaçamento entre linhas na severidade de doenças, principalmente da ferrugem-asiática da soja, exceto pelos trabalhos realizados por Madalosso et al. (15) e Soares \& Lonien (22).

Sabe-se que o desenvolvimento de uma doença depende da interação entre planta, agente patogênico e fatores ambientais $(1,2,7$, 20). Portanto o ambiente, representado tanto pelas condições meteorológicas como pelo micro clima, é um fator relevante nesta 
relação, e cada epidemia causada por um mesmo patógeno terá um desenvolvimento diferente, dependendo do local e do ano de sua ocorrência (1). Para a ferrugem-asiática da soja já foi observada relação entre duração do período de molhamento foliar com o aparecimento dos primeiros sintomas da doença e também relação entre número de dias de chuva com o progresso da epidemia (24). O uso de espaçamento e densidade de plantas adequado a uma cultura evita a formação de micro clima favorável a doenças, ao promover boas condições de arejamento e luminosidade para as plantas e evitar acúmulo de umidade, que favorece o patógeno $(1,2)$; enquanto o adensamento de plantas promove aumento de temperatura e umidade do ar, podendo favorecer o desenvolvimento de doenças e influenciar na produtividade, como observado por Blad et al. (4) para o mofo branco no feijoeiro e por Buzzel et al. (5) para o mofo branco na soja. Estes autores avaliaram três espaçamentos (23, 45 e $69 \mathrm{~cm}$ ) entre linhas de soja, no Sudeste do Canadá, e concluíram não haver diferença entre os espaçamentos, para severidade de mofo branco (Sclerotinia sclerotiorum), no entanto observaram que nos menores espaçamentos a produtividade foi maior do que com $69 \mathrm{~cm}$ entre linhas. Joye et al. (14) observaram, no Sul dos Estados Unidos, que a severidade da mela (Rhizoctonia solani) e a produtividade de grãos de soja foram afetados pelos espaçamentos de 25, 50, 75 e $100 \mathrm{~cm}$ entre linhas. Hanna et al. (12) observaram, no Nordeste dos Estados Unidos, que o espaçamento entre linhas não afetou a penetração do fungicida no dossel das plantas; no entanto, maior produtividade foi obtida em espaçamentos menores (19 e 38 $\mathrm{cm})$ do que em espaçamento maior $(76 \mathrm{~cm})$.

Para a ferrugem-asiática da soja, Madalosso et al. (15), observaram, no Rio Grande do Sul, que espaçamentos entre linhas de $40 \mathrm{~cm}$ e $50 \mathrm{~cm}$ foram mais favoráveis ao progresso da doença e diminuíram a eficácia do controle químico por meio da pulverização de fungicida, enquanto o espaçamento de $60 \mathrm{~cm}$ proporcionou menor severidade de doença e maior produtividade. Soares \& Lonien (22) verificaram que, entre os espaçamentos de 45 e $60 \mathrm{~cm}$ entre linhas, não houve diferença na severidade de ferrugem e no peso de mil grãos. No entanto, o maior espaçamento proporcionou melhor penetração do fungicida e menor desfolha das plantas.

O presente trabalho teve como objetivo avaliar o efeito do espaçamento entre linhas de semeadura de soja, com e sem aplicação de fungicida, na severidade da ferrugem-asiática e na produtividade.

\section{MATERIAL E MÉTODOS}

Os experimentos foram realizados na área experimental da Embrapa Agropecuária Oeste, em Dourados, MS, em solo classificado como latossolo vermelho distroférrico típico (latitude $22^{\circ} 16^{\prime} \mathrm{S}$, longitude $54^{\circ} 49^{\prime} \mathrm{O}$, altitude média de $408 \mathrm{~m}$ ), em delineamento de blocos ao acaso com quatro repetições, em esquema fatorial $4 \times 2$. Foram avaliados os espaçamentos de 35, 45, 55 e 65 cm entre linhas, com e sem aplicação de 150 litros por hectare de calda fungicida contendo azoxistrobina + ciproconazole $(60+24$ gramas de ingrediente ativo por hectare, respectivamente) acrescido de óleo mineral parafínico Nimbus ( $0,5 \%$ do volume da calda de aplicação) na parte aérea das plantas, totalizando assim oito parcelas por bloco. Foram realizadas duas aplicações de fungicida, sendo a primeira no estádio R2 (florescimento pleno) e a segunda 21 dias após a primeira. Os experimentos foram realizados em três safras, cada uma com uma cultivar de soja diferente. As cultivares e as datas de semeadura foram: BRS $256 \mathrm{RR}$ semeada em 12/12/2007, BRS 246 RR semeada em 20/11/2009 e BRS 318 RR semeada em 07/12/2010. Em todos os tratamentos, a quantidade de sementes foi ajustada para se obter população de 300 mil plantas por hectare, e a adubação de base da fórmula 0:20:20 de N:P:K foi calculada para 300 quilogramas por hectare, independente do espaçamento utilizado. As parcelas foram constituídas por seis linhas de $6 \mathrm{~m}$ de comprimento, espaçadas de acordo com os tratamentos. A adubação e a semeadura foram realizadas manualmente. O manejo cultural da soja durante toda a condução dos experimentos foi realizado de acordo com o preconizado na literatura (23).

As avaliações foram realizadas nas quatro linhas centrais de cada parcela, descartando-se o metro inicial e final de cada linha. Avaliou-se a severidade da ferrugem em pelo menos três estádios de desenvolvimento em cada safra, o que permitiu calcular a área abaixo da curva de progresso da doença (AACPD), de acordo com a seguinte fórmula: AACPD $={ }_{i} \Sigma^{\mathrm{n}-1}\left[\left(\mathrm{x}_{\mathrm{i}}+\mathrm{x}_{\mathrm{i}+1}\right)\right] / 2\left(\mathrm{t}_{\mathrm{i}+1}-\mathrm{t}_{\mathrm{i}}\right)$, onde $n$ é o número de avaliações, $x$ é a severidade da doença e $\left(t_{i+1}-t_{i}\right)$ é o intervalo de tempo entre duas avaliações consecutivas (21). Após a colheita avaliou-se também o rendimento de grãos, ajustado para $13 \%$ de umidade. A severidade da doença foi estimada com auxílio de escala diagramática (10), avaliando-se no mínimo dez folíolos em cada terço (superior, médio e inferior) das plantas, para obter o valor médio de severidade da parcela.

Devido ao emprego de cultivares de soja e datas de semeadura diferentes, a análise dos dados foi realizada separadamente para cada safra. Na safra 2007/2008 as avaliações de severidade da ferrugem foram realizadas nos estádios R2, R5.3 e R7.1 da escala de Fehr \& Caviness (9) revisada por Ritchie et al. (19). Na safra 2009/2010 as avaliações foram realizadas nos estádios R5.1, R5.3, R5.4 e R5.5. Na safra 2010/2011 as avaliações foram realizadas nos estádios R4, R5.4 e R5.5. Para análise estatística da severidade foram usados os dados da última avaliação, exceto na safra 2007/2008, quando foram utilizaram os dados da avaliação realizada em R5.3, pois na última avaliação os sintomas já estavam muito avançados, dificultando a distinção entre os tratamentos. As demais avaliações contribuíram para o cálculo da AACPD.

As análises estatísticas foram realizadas com auxílio do programa R (18), realizando a análise de variância e comparação de médias pelo ajuste de modelos de regressão (para o efeito do espaçamento entre linhas) e pelo teste de comparação múltipla de médias de Tukey, a 5\% (para o efeito da aplicação de fungicida), quando significativos a 5\% pelo teste $\mathrm{F}$ da análise de variância.

\section{RESULTADOS E DISCUSSÃO}

Na safra 2007/2008, com a cultivar BRS 256 RR, a doença iniciou na fase vegetativa, sendo constatada na área experimental cinco dias antes do início do florescimento. Quando realizada a primeira aplicação de fungicida, no estádio R2, as plantas já apresentavam média de $6,8 \%$ de severidade. Não houve interação significativa entre aplicação de fungicida e espaçamento entre linhas, para nenhum dos resultados obtidos (severidade, AACPD e produtividade) (Tabela 1). A aplicação de fungicida reduziu a severidade da doença e a AACPD, aumentando a produtividade (Tabela 2). Os espaçamentos entre linhas não influenciaram a severidade, a AACPD e a produtividade. (Figura 1).

Na safra 2009/2010, com a cultivar BRS 246 RR, os primeiros sinais da ferrugem foram observados na área experimental por ocasião da primeira aplicação de fungicida (R2), porém com severidade inferior a $0,6 \%$ (valor mínimo da escala utilizada). Não houve interação significativa entre aplicação de fungicida e espaçamento entre linhas, tanto para severidade quanto para AACPD (Tabela 3). A aplicação de 
Tabela 1. Análise de variância para severidade da ferrugem-asiática no estádio R5.3, área abaixo da curva de progresso da doença (AACPD) e produtividade de soja, em função de aplicação de fungicida e quatro espaçamentos entre linhas, na safra 2007/2008 em Dourados, MS.

\begin{tabular}{lrrrrrr}
\hline \multirow{2}{*}{ Fator } & \multicolumn{2}{c}{ Severidade } & \multicolumn{2}{c}{ AACPD } & \multicolumn{2}{c}{ Produtividade } \\
\cline { 2 - 7 } & \multicolumn{1}{c}{$\mathbf{F c}$} & $\mathbf{P r}>\mathbf{F c}$ & $\mathbf{F c}$ & $\mathbf{P r}>\mathbf{F c}$ & $\mathbf{F c}$ & $\mathbf{P r}>\mathbf{F c}$ \\
\hline Fungicida & 2930,33 & 0,000000 & 2099,11 & 0,00000 & 124,987 & 0,00000 \\
Espaçamento & 1,55 & 0,231928 & 1,39 & 0,27467 & 0,941 & 0,43835 \\
Fun*Esp & 1,55 & 0,231928 & 1,61 & 0,21696 & 0,20660 \\
\hline CV (\%) & & 3,8 & & 9,1 & & 26,4 \\
\hline
\end{tabular}

Tabela 2. Valores médios da severidade em R5.3 (\%), área abaixo da curva de progresso da doença (AACPD) e produtividade (kg ha ${ }^{-1}$ ) de soja cv. BRS 256 RR, em função da aplicação de fungicida (azoxistrobina + ciproconazole), na safra 2007/2008 em Dourados, MS.

\begin{tabular}{lcrrrr}
\hline Tratamento & Severidade & em R5.3 (\%) & \multicolumn{2}{c}{ AACPD } & \multicolumn{2}{c}{ Produtividade (kg ha $^{-1}$ ) } \\
\hline Com fungicida & $31,2 \mathrm{~b}$ & 316,6 & $\mathrm{~b}$ & 1.795 & $\mathrm{a}$ \\
Sem fungicida & $66,7 \quad \mathrm{a}$ & $2.075,4$ & $\mathrm{a}$ & $565 \quad \mathrm{~b}$ & \\
\hline
\end{tabular}

Médias de quatro espaçamentos entre linhas $(35,45,55$ e $65 \mathrm{~cm})$. Médias seguidas pela mesma letra, na coluna, são estatisticamente semelhantes (Tukey, $\mathrm{pd} \leq 0,05)$.
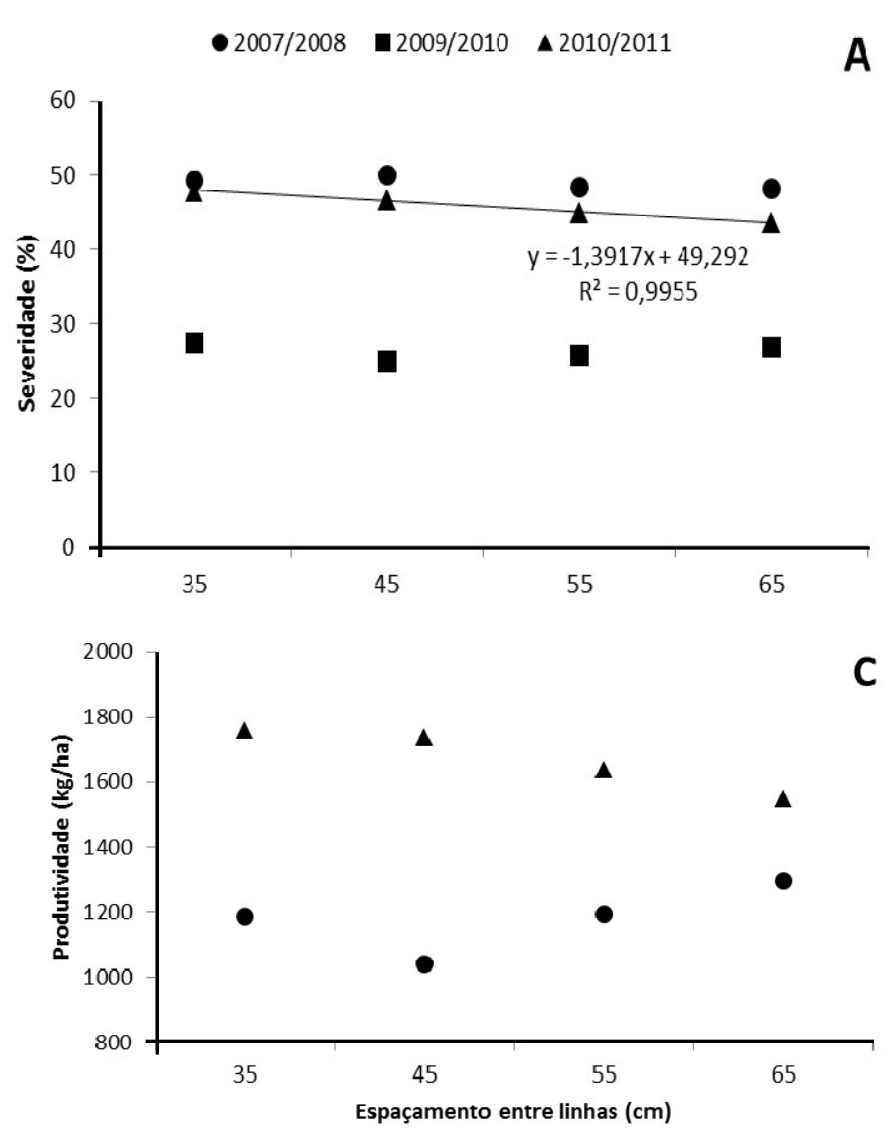

fungicida reduziu a severidade da doença e a AACPD (Tabela 4), enquanto que as médias dos espaçamentos entre linhas foram estatisticamente iguais (Figura 1). Para produtividade de grãos houve interação entre aplicação de fungicida e espaçamento entre linhas (Tabela 3). Somente no espaçamento de $45 \mathrm{~cm}$ entre linhas a aplicação de fungicida proporcionou produtividade superior ao tratamento sem fungicida (Tabela 4), sendo igual nos demais espaçamentos. O efeito do espaçamento não foi observado nas parcelas com aplicação de fungicida. Nas parcelas sem aplicação de fungicida o espaçamento foi

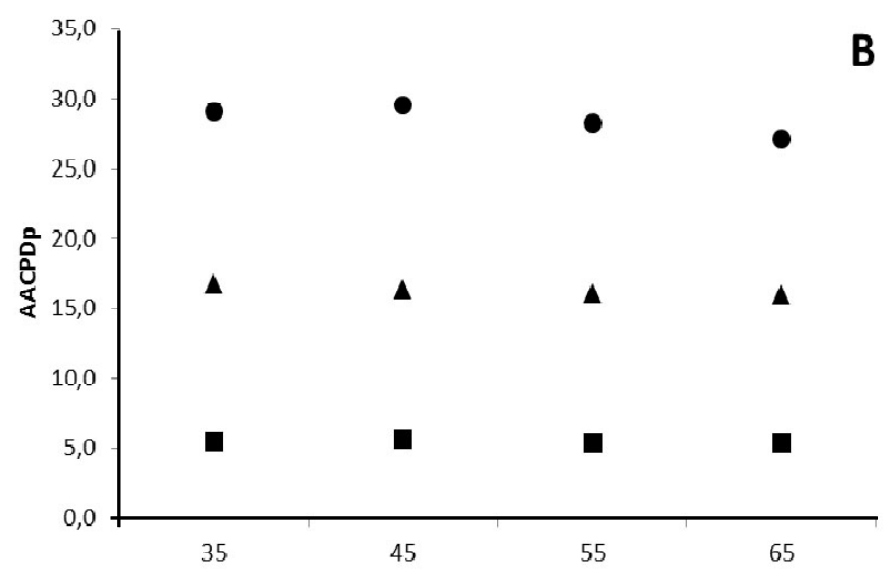

Figura 1. Severidade de ferrugem-asiática (A), área abaixo da curva de progresso da doença padronizada, conforme Campbell \& Madden (6) (B) e produtividade (C) de soja sob diferentes espaçamentos entrelinhas. Cultivares são: BRS 256 RR na safra 2007/2008, BRS 246 RR na safra 2009/2010 e BRS 318 RR na safra 2010/2011. Médias de parcelas com e sem aplicação de fungicida.

significativo, no entanto não se encontrou um ajuste com significado biológico. (Figura 2).

Na safra 2010/2011, com a cultivar BRS 318 RR, assim como aconteceu na safra anterior, os primeiros sinais da ferrugem foram observados na área experimental quando da realização da primeira aplicação de fungicida (R2). Não houve interação entre aplicação de fungicida e espaçamento entre linhas para nenhuma das avaliações realizadas (Tabela 5). Houve efeito de fungicida para severidade, AACPD e produtividade, aumentando a produtividade e reduzindo a 
Tabela 3. Análise de variância para severidade da ferrugem-asiática no estádio R5.5, área abaixo da curva de progresso da doença (AACPD) e produtividade de soja, em função de aplicação de fungicida e quatro espaçamentos entre linhas, na safra $2009 / 2010$ em Dourados, MS.

\begin{tabular}{|c|c|c|c|c|c|c|}
\hline \multirow[t]{2}{*}{ Fator } & \multicolumn{2}{|c|}{ Severidade* } & \multicolumn{2}{|c|}{ AACPD } & \multicolumn{2}{|c|}{ Produtividade } \\
\hline & Fc & Pr $>$ Fc & Fc & Pr $>$ Fc & Fc & Pr $>$ Fc \\
\hline Fungicida & 129,558 & 0,00000 & 93,702 & 0,00000 & 5,6222 & 0,027377 \\
\hline Espaçamento & 1,131 & 0,35913 & 0,061 & 0,97991 & 2,6402 & 0,076045 \\
\hline Fun*Esp & 0,365 & 0,77929 & 0,755 & 0,53192 & 4,0975 & 0,019487 \\
\hline CV (\%) & \multicolumn{2}{|c|}{6,3} & \multicolumn{2}{|c|}{26,8} & \multicolumn{2}{|c|}{13,5} \\
\hline
\end{tabular}

*Dados transformados para arc.sen.raiz de $\times 100^{-1}$.

Tabela 4. Valores médios da severidade em R5.5 (\%), área abaixo da curva de progresso da doença (AACPD) e produtividade (kg ha-1) de soja cv. BRS 246 RR, em função da aplicação de fungicida (azoxistrobina + ciproconazole), na safra 2009/2010 em Dourados, MS.

\begin{tabular}{ccccc}
\hline Tratamento & Severidade em R5.5 (\%)* & AACPD & Produtividade (kg ha $\left.{ }^{-1}\right)$ \\
\hline Com fungicida & $20,3 \mathrm{~b}$ & $73,5 \mathrm{~b}$ & $2.318 \mathrm{a}$ \\
Sem fungicida & $32,2 \mathrm{a}$ & $198,2 \mathrm{a}$ & $1.668 \mathrm{~b}$ & \\
\hline
\end{tabular}

Médias de quatro espaçamentos entre linhas $(35,45,55$ e $65 \mathrm{~cm})$, exceto para produtividade, onde observou-se interação entre aplicação de fungicida e espaçamento. Neste caso as médias são somente para o espaçamento de $45 \mathrm{~cm}$, pois os demais são estatisticamente iguais. Médias seguidas pela mesma letra, na coluna, são estatisticamente semelhantes (Tukey, $\mathrm{p} \leq 0,05$ ). *Para análise estatística os dados foram transformados para arc.sen.raiz de $\mathrm{x} 100^{-1}$.

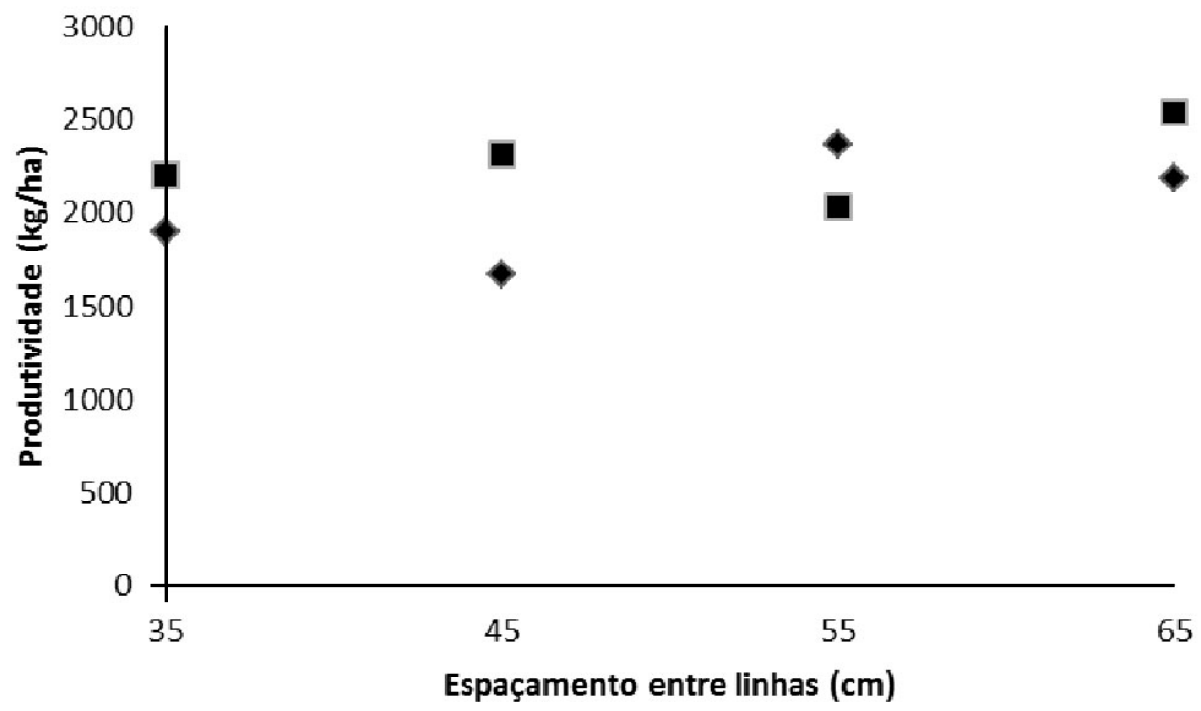

Figura 2. Produtividade de soja cv. BRS 246 RR, com aplicação $(\boldsymbol{\square})$ e sem aplicação $(\diamond)$ de fungicida em função de diferentes espaçamentos entre linhas, na safra 2009/2010, em Dourados, MS.

severidade e a AACPD (Tabela 6). Observou-se que o aumento do espaçamento entre linhas reduziu a severidade da ferrugem, ajustandose ao modelo linear de regressão (Figura 1), na média das parcelas com e sem aplicação de fungicida, enquanto que para AACPD e produtividade não houve efeito de espaçamento entre linhas.

Neste trabalho observou-se que a interação entre espaçamento entre linhas e aplicação de fungicida ocorreu somente para a produtividade na safra 2009/2010, quando a aplicação de fungicida influenciou a produtividade somente no espaçamento de $45 \mathrm{~cm}$ (Tabela 4) e não alterou a produtividade nos demais espaçamentos entre linhas. Nas parcelas sem fungicida, maior produtividade de soja foi observada entre os espaçamentos de 55 e $65 \mathrm{~cm}$ entre linhas (Figura 2), sendo que nas parcelas com aplicação de fungicida não foi observado efeito do espaçamento na produtividade. Para severidade da ferrugem e AACPD não houve interação entre aplicação de fungicida e espaçamento entre linhas.
Analisando os efeitos dos fatores isolados, observou-se que a aplicação de fungicida controlou a doença, proporcionando redução da severidade e da AACPD nas três safras, e aumento da produtividade na primeira e terceira safras (Tabelas 2,4 e 6 ). $\mathrm{O}$ espaçamento entre linhas, por sua vez, somente influenciou a severidade da ferrugem na terceira safra (Figura 1), não interferindo na AACPD em nenhuma das safras avaliadas e nem na produtividade na primeira e terceira safras.

Os resultados obtidos neste trabalho confirmam a eficiência do controle químico da ferrugem-asiática da soja através da pulverização de fungicida, e mostram, ainda, que o efeito do espaçamento entre linhas na severidade da ferrugem e na produtividade de grãos é variável, dependendo da safra e da cultivar. Quando resultados significativos foram observados para o fator espaçamento, o aumento deste para distâncias superiores ao padrão de $45 \mathrm{~cm}$ proporcionou diminuição na severidade da doença (Figura 1) ou aumento na produtividade de parcelas sem aplicação de fungicida (Figura 2). 
Tabela 5. Análise de variância para severidade da ferrugem-asiática no estádio R5.5, área abaixo da curva de progresso da doença (AACPD) e produtividade de soja, em função de aplicação de fungicida e quatro espaçamentos entre linhas, na safra 2010/2011 em Dourados, MS.

\begin{tabular}{crrrrrr}
\hline \multirow{2}{*}{ Fator } & \multicolumn{2}{c}{ Severidade* } & \multicolumn{2}{c}{ AACPD } & \multicolumn{2}{c}{ Produtividade } \\
\cline { 2 - 7 } & \multicolumn{1}{c}{ Fc } & Pr>Fc & Fc & Pr>Fc & Fc & Pr>Fc \\
\hline Fungicida & 146,179 & 0,000000 & 47,424 & 0,00000 & 0,00150 \\
Espaçamento & 7,467 & 0,001383 & 0,837 & 0,48883 & 1,1473 \\
Fun*Esp & 2,984 & 0,054445 & 1,762 & 0,18515 & 0,9424 & 0,43792 \\
\hline CV (\%) & \multicolumn{2}{c}{$\mathbf{4 , 1}$} & & $\mathbf{6 , 7}$ & $\mathbf{1 5 , 4}$ \\
\hline
\end{tabular}

*Dados transformados para arc.sen.raiz de $\times 100^{-1}$.

Tabela 6. Valores médios da severidade em R5.5 (\%), área abaixo da curva de progresso da doença (AACPD) e produtividade (kg ha ${ }^{-1}$ ) de soja cv. BRS 318 RR, em função da aplicação de fungicida (azoxistrobina + ciproconazole), na safra 2010/2011 em Dourados, MS.

\begin{tabular}{|c|c|c|c|}
\hline Tratamento & Severidade em R5.5 (\%)* & AACPD & Produtividade $\left(\mathrm{kg} \mathrm{ha}^{-1}\right)$ \\
\hline Sem fungicida & 49,79 a & $352,62 \quad a$ & $1.505 \mathrm{~b}$ \\
\hline
\end{tabular}

Médias de quatro espaçamentos entre linhas $(35,45,55$ e $65 \mathrm{~cm})$. Médias seguidas pela mesma letra, na coluna, são estatisticamente semelhantes (Tukey, $\mathrm{p} \leq 0,05$ ).

Esses resultados confirmam os obtidos por Madalosso et al. (15), que observaram aumento da produtividade no espaçamento de $60 \mathrm{~cm}$ entre linhas e maior severidade da doença nos espaçamentos de 40 e $50 \mathrm{~cm}$, e concordam parcialmente com os resultados obtidos por Soares \& Lonien (22), os quais não observaram diferenças na severidade da doença e no peso de mil grãos entre os espaçamentos de 45 e $60 \mathrm{~cm}$ entre linhas, porém observaram que o maior espaçamento facilitou o controle da doença e reduziu a desfolha.

Observando-se os dados de precipitação pluviométrica nas safras avaliadas, tanto durante os períodos de condução dos experimentos quanto nos períodos de vazio sanitário que antecederam as safras, não se observa diferenças de precipitação que suportem diferenças na severidade da ferrugem entre as safras avaliadas. $\mathrm{O}$ número de dias com chuva, registrado pela estação meteorológica da Embrapa Agropecuária Oeste durante a condução dos experimentos, foi de 46 $(706 \mathrm{~mm}), 45(862 \mathrm{~mm})$ e $48(688 \mathrm{~mm})$, respectivamente para a primeira, segunda e terceira safra. No entanto, na safra 2007/2008 o experimento foi semeado em 12 de dezembro, quando grande parte das lavouras de soja na região já estava iniciando o florescimento, podendo ter sido influenciado por um maior inoculo inicial e consequente surgimento da doença mais cedo na área experimental. Quando realizada a primeira aplicação de fungicida nesta safra, as plantas já apresentavam, em média, 6,8\% de severidade. Este fato pode ter dificultado a observação do efeito do aumento do espaçamento entre linhas na severidade da ferrugem e, consequentemente, na produtividade.

Efeito do espaçamento foi observado nas safras 2009/2010 (para produtividade) e 2010/2011 (para severidade), quando as semeaduras foram, respectivamente, em 20 de novembro e 7 de dezembro, os primeiros sinais da ferrugem foram observados no experimento somente no estádio R2 e a severidade final da doença foi menor do que na primeira safra. Pode-se inferir, portanto, que o aumento do espaçamento entre linhas se semeadura é uma estratégia passível de ser inserida ao manejo integrado da ferrugem-asiática da soja, principalmente quando as semeaduras são realizadas no início da época recomendada pelo zoneamento agrícola, pois proporcionou redução da severidade na cultivar BRS $318 \mathrm{RR}$, contribuindo para o manejo da doença.

\section{REFERÊNCIAS BIBLIOGRÁFICAS}

1. Aust, H.J.; Hoyningen-Huene, J.V. Microclimate in relation to epidemics of powdery mildew. Ann. Rev. Phytopathol., Palo Alto, v.24, p.491-510, 1986.

2. Bedendo, I.P. Ambiente e doença. In: Bergamin Filho, A.; Kimati, H.; Amorim, L. (Ed.) Manual de fitopatologia: princípios e conceitos. São Paulo: Ceres, 1995. v.1, cap.18, p.331-341.

3. Bianchi, M.A.; Fleck, N.G.; Lamego, F.P.; Agostinetto, D. Papéis do arranjo de plantas e do cultivar de soja no resultado da interferência com plantas competidoras. Planta Daninha, Viçosa, MG, v.28, p.979-991, 2010. Número especial.

4. Blad, B.L.; Steadman, J.R.; Weiss, A. Canopy structure and irrigation influence white mold disease and microclimate of dry edible beans. Phytopathology, St. Paul, v.68, p.1431-1437, 1978.

5. Buzzell, R.I.; Welacky, T.W.; Anderson, T.R. Soybean cultivar reaction and row width effect on Sclerotinia stem rot. Canadian Journal of Plant Science, Ottawa, v.73, n.4, p.1169-1175, 1993.

6. Campbell, C.L.; Madden, L.V. Introduction to plant disease epidemiology. New York: Jonh Wiley, 1990. 532p.

7. Colhoun, J. Effects of environmental factors on plant disease. Ann. Rev. Phytopathol., Palo Alto, v.11, p.343-364, 1973.

8. Crusciol, C.A.C.; Machado, J.R.; Arf, O.; Rodrigues, R.A.F. Rendimento de benefício e de grãos inteiros em função do espaçamento e da densidade de semeadura do arroz de sequeiro. Scientia Agricola, Piracicaba, v. 56, n. 1, p. 47-52, 1999.

9. Fehr, W.R.; Caviness, C.E. Stages of soybean development. Ames, Iowa State University of Science and Technology, 1977. $11 \mathrm{p}$.

10. Godoy, C.V.; Koga, L.J.; Canteri, M.G. Diagrammatic scale for assessment of soybean rust severity. Fitopatologia Brasileira, Brasília, DF, v.31, n.1, p.63-68, 2006.

11. Guidolin, A.F.; Merotto Junior, A.; Ender, M.; Sangoi, L.; Duarte, I.A. Efeitos do arranjo e da população de plantas sobre o crescimento do feijão em semeadura tardia. Ciência Rural, Santa Maria, RS, v.28, n.4, p.547-551, 1998.

12. Hanna, S.O.; Conley, S.P.; Shaner, G.E.; Santini, J.B. Fungicide application timing and row spacing effect on soybean canopy penetration and grain yield. Agronomy Journal, Madison, v.100, n.5, p.1488-1492, 2008.

13. Heiffig, L.S.; Câmara, G.M.S.; Marques, L.A.; Pedroso, D.B.; Piedade, S.M.S. Fechamento e índice de área foliar da cultura da soja em diferentes arranjos espaciais. Bragantia, Campinas, v.65, 
n.2, p.285-295, 2006 .

14. Joye, G.F.; Berggren, G.T.; Berner, D.K. Effects of row spacing and within-row plant population on Rhizoctonia Aerial Blight of soybean and soybean yield. Plant Disease, St. Paul, v.74, n.2, p.158-160, 1990

15. Madalosso, M.G.; Domingues, L.S.; Debortoli, M.P.; Lenz, G.; Balardin, R.S. Cultivares, espaçamento entrelinhas e programas de aplicação de fungicidas no controle de Phakopsora pachyrhizi Sidow em soja. Ciência Rural, Santa Maria, RS, v.40, n.11, p.2256-2261, 2010 .

16. Napoleão, R.; Café Filho, A.C.; Lopez, C.A.; Nasser, L.C.B. Efeito do espaçamento e da cultivar de feijoeiro sobre a intensidade do mofo-branco e a sanidade de sementes. Summa Phytopathologica, Botucatu, v.32, n.1, p.63-66, 2006.

17. Rambo, L.; Costa, J.A.; Pires, J.L.F.; Parcianello, G.; Ferreira, F.G. Rendimento de grãos da soja em função do arranjo de plantas. Ciência Rural, Santa Maria, RS, v.33, n.3, p.405-411, 2003.

18. R: a language and environment for statistical computing. Vienna: R Foundation for Statistical Computing, 2011. 409p. Disponível em: <http://www.R-project.org $>$. Acesso em: 07 de fevereiro de 2012 .

19. Ritchie, S.W.; Hanway, J.J.; Thompson, H.E.; Benson, G.O. How a soybean plant develops. Ames, Iowa State University of Science and Technology: Cooperative Extension Service, 1994. 20 p. (Special Report, 53).

20. Shaner, G. Effect of environment on fungal leaf blights of small grains. Ann. Rev. Phytopathol., Palo Alto, v.19, p.273-296, 1981.

21. Shaner, G.; Finney, R.E. The effect of nitrogen fertilization on the expression of slow-mildewing resistance in Knox wheat. Phytopathology, St. Paul, v. 67, p. 1051-1056, 1977.

22. Soares, R.M.; Lonien, G. Efeito do espaçamento entrelinhas no desenvolvimento e controle da ferrugem da soja. Fitopatologia Brasileira, Brasília, DF, v.32, supl., p.S256-S256, 2007. (Resumo).

23. Tecnologias de produção de soja região Central do Brasil 2011. Londrina: Embrapa Soja: Embrapa Cerrados: Embrapa Agropecuária Oeste, 2010. 255p. (Embrapa Soja. Sistemas de produção, $14)$.

24. Tsukahara, R.Y.; Hikishima, H.; Canteri, M.G. Relação entre o clima e o progresso da ferrugem-asiática (Phakopsora pachyrhi$z i)$ em duas micro-regiões do Estado do Paraná. Semina: Ciências Agrárias, Londrina, v.29, p.47-52, 2008.

25. Yorinori, J.T.; Paiva, W.M.; Frederick, R.D.; Costamilan, L.M.; Bertagnolli, P.F.; Hartman, G.E.; Godoy, C.V.; Nunes Júnior., J. Epidemics of soybean rust (Phakopsora pachyrhizi) in Brazil and Paraguay from 2001 to 2003. Plant Disease, St. Paul, v.89, n.6, p.675-677, 2005 . 